NASA Technical Memorandum 106152

AIAA-93-2037

\title{
Experimental Investigation of Crossflow Jet Mixing in a Rectangular Duct
}

D.S. Liscinsky and B. True

United Technologies Research Center

East Hartford, Connecticut

and

J.D. Holdeman

Lewis Research Center

Cleveland, Ohio

Prepared for the

29th Joint Propulsion Conference and Exhibit

cosponsored by the AIAA, SAE, ASME, and ASEE

Monterey, California, June 28-30, 1993 


\title{
EXPERIMENTAL INVESTIGATION OF CROSSFLOW JET MIXING
}

\author{
IN A RECTANGULAR DUCT \\ D.S. Liscinsky ${ }^{*}$ and B. True ${ }^{* *}$ \\ United Technologies Research Center \\ East Hartford, CT 06108
J.D. Holdeman ${ }^{\dagger}$
NASA Lewis Research Center
Cleveland, $\mathrm{OH} \quad \mathbf{4 4 1 3 5}$

\section{Abstract}

An experimental investigation of the mixing of nonreacting opposed rows of jets injected normal to a confined rectangular crossflow has been conducted. Planar Mie-scattering was used to measure the time-average concentration distribution of the jet fluid in planes perpendicular to the duct axis. The mixing effectiveness of round orifice injectors was measured as a function of orifice spacing and orifice diameter. Mixing effectiveness was determined using a spatial unmixedness parameter based on the variance of mean jet concentration distributions. Optimum mixing was obtained when the spacing-to-duct-height ratio was inversely proportional to the square root of the jet-to-mainstream momentumflux ratio. For opposed rows of round holes with centerlines inline, mixing was similar for blockages up to $75 \%$. Lower levels of unmixedness were obtained as a function of downstream location when axial injection length was minimized. Mixing may be enhanced if orifice centerlines of opposed rows are staggered, but note that blockage must be $\leq 50 \%$ for this configuration.

\section{Nomenclature}

\begin{tabular}{|c|c|}
\hline$A_{j} / A_{m}$ & $\begin{array}{l}\text { jet-to-mainstream area ratio } \\
=(\pi / 2)(\mathrm{S} / \mathrm{H}) /(\mathrm{S} / \mathrm{D})^{2}\end{array}$ \\
\hline B & blockage $=y$ projection $/ \mathrm{S}$ \\
\hline $\mathrm{C}$ & $(\mathrm{S} / \mathrm{H}) * \sqrt{\mathrm{J}}($ see Eq. 3$)$ \\
\hline$c$ & $\begin{array}{l}\text { fully mixed mass fraction } \\
=\left(w_{j} / w_{m}\right) /\left(1+w_{j} / w_{m}\right)=\theta_{E B},(\text { Ref. } 2)\end{array}$ \\
\hline $\mathrm{C}_{\mathrm{d}}$ & orifice discharge coefficient \\
\hline $\mathrm{D}$ & orifice diameter \\
\hline H & duct height at injection plane $=2$ in \\
\hline $\mathrm{J}$ & $\begin{array}{l}\text { jet-to-mainstream momentum-flux ratio } \\
=\left(\rho_{j} V_{j}^{2}\right) /\left(\rho_{m} V_{m}^{2}\right)\end{array}$ \\
\hline p & density \\
\hline$S$ & spacing between adjacent orifice mid-points \\
\hline $\mathrm{U}_{\mathrm{S}}$ & spatial unmixedness parameter (Eq. 2) \\
\hline $\mathrm{V}_{\mathrm{m}}$ & mainstream velocity $=10 \mathrm{ft} / \mathrm{s}$ \\
\hline & jet velocity $=w_{j} / \rho_{j} A_{j} C_{d}$ \\
\hline wi/wm & jet-to-mainstream mass flow rati \\
\hline
\end{tabular}

* Research Scientist, Member AIAA

** Senior Laboratory Technician

$\dagger$ Senior Research Engineer, Associate Fellow AIAA
Nomenclature (cont.)

$x$ downstream coordinate, $x=0$ at the upstream
edge of the orifice
cross-stream coordinate

Introduction

The injection of jets normal to a crossflow is a commonly employed mixing technique. One important application is the dilution zone of a gas turbine combustor which typically uses rows of relatively cool air jets to lower the exit temperature of the combustor. This mixing technique is also under evaluation as a key technology for the development of an advanced low $\mathrm{NO}_{\mathrm{x}}$ engine based on a Rich-Burn/Quick-Mix/ Lean-Burn(RQL) combustor ${ }^{1}$. The RQL combustor depends on an efficient quick mix section that rapidly and uniformly dilutes the rich zone products to minimize emissions.

Extensive cross flow mixing investigations reported by Holdeman ${ }^{2}$ have focussed on conventional gas turbine dilution zones where up to $30 \%$ of the total flow was introduced with the dilution jets. Recently other studies of jets in a rectangular cross flow have been reported by $\mathrm{Smith}^{3}$, Bain, Smith, \& Holdeman ${ }^{4}$, and Liscinsky et al..$^{5,6}$, while studies of confined jets in cylindrical ducts have been reported by Talpallikar et al. ${ }^{7}$, Smith, Talpallikar, \& Holdeman ${ }^{8}$, Vranos et al. ${ }^{9}$. Hatch et al. ${ }^{10}$, Oechsle, Mongia, \& Holdeman ${ }^{11}$, and Kroll et al. ${ }^{12}$ These studies all conclude that the rate of mixing by a row of jets in cross flow is primarily determined by the jet-tomainstream momentum-flux ratio $(\mathrm{J})$ and the orifice spacingto-duct height ratio $(\mathrm{S} / \mathrm{H})$.

In the RQL combustor the jet fluid introduced in the quick mix section accounts for up to $75 \%$ of the total flow. Since the available pressure drop is limited, injection of large mass flows through discrete orifices requires jet-to-mainstream area ratios larger than those considered when studying conventional dilution zones. In this investigation the effects of closely spaced orifices $(S / D<2)$ are compared to the conclusions of previous studies where larger orifice spacing was evaluated. 


\section{Experimental}

Figure 1 is a schematic representation of the cross flow mixing apparatus. The apparatus consists of 3 parallel contiguous ducts of rectangular cross section, simulating a sector of an annular combustor. Sector width is 12 inches. The inner duct height $(\mathrm{H})$ is variable, but was set at 2 inches for the reported experiments. The outer ducts (shrouds), which supply the injectant gas, are 1 inch in height. These are separated from the inner duct by removable, 0.12 inch thick flat plates. The injectant is fed from the shrouds to the inner duct through orifices of various sizes and shapes that are machined into the plates. Mass flow to each of the 3 ducts is controlled independently using venturi flowmeters. The mean mainstream flow velocity was $10 \mathrm{ft} / \mathrm{sec}$ with less than $6 \%$ variation across the duct and a turbulence level of $1.3 \%$. All tests were conducted with unity density ratio.

Planar digital imaging was used to optically measure concentration distributions in planes perpendicular to the duct axis beginning at the trailing-edge of the orifice. The Miescattering technique is applied by marking the jet flow with an oil aerosol ( $\mu \mathrm{m}$ sized particles). A light sheet ( 0.02 inch thick) is created using a $2 \mathrm{~W}$ argon-ion laser and a rotating mirror. The flow field is illuminated by passing the light sheet through a window in the side wall of the test section. An image intensified thermo-electrically cooled CCD camera, located inside the duct $2.5 \mathrm{ft}$ downstream of the orifice centerline, is focused on the illuminated plane (end-on view). The camera is programmed to make exposures coincident with the sweep of the beam through the flow field. The image is digitized at a spatial resolution of $0.02 \times 0.02 \mathrm{inch} / \mathrm{pixel}$ in a $576 \times 100$ pixel format and sent to a computer for storage. The scattered light intensity is proportional to the number of particles in the measurement volume. If only one of two streams is marked, the light intensity of the undiluted marked fluid represents mole fraction unity.
An unmixedness parameter that quantifies temporal fluctuations was defined by Danckwertz ${ }^{13}$ as,

$$
\begin{aligned}
& \text { where, } \\
& \qquad \begin{aligned}
\mathrm{c}^{\prime 2} & =\frac{1}{\mathrm{n}} \frac{1}{\mathrm{~m}} \sum_{\mathrm{j}=1}^{\mathrm{n}} \sum_{\mathrm{i}=1}^{\mathrm{m}}\left(\mathrm{c}_{\mathrm{ij}}-\overline{\mathrm{c})^{2}}=\right.\text { concentration variance } \\
\mathrm{n} & =\text { number of images in data set } \\
\mathrm{m} & =\text { number of pixels in each image } \\
\mathrm{c}_{\mathrm{ij}} & =\text { instantaneous concentration at a pixel } \\
\overline{\mathrm{c}}= & \frac{1}{\mathrm{n}} \frac{1}{\mathrm{~m}} \sum_{\mathrm{j}=1}^{\mathrm{n}} \sum_{\mathrm{i}=1}^{\mathrm{m}} \mathrm{c}_{\mathrm{ij}}=\text { concentration mean } \\
& =\text { fully mixed concentration } \\
\overline{\mathrm{c}}(1-\overline{\mathrm{c}})=\text { maximum concentration variance } & =0.188 \text { for a jet-mainstream flow split of } 3: 1
\end{aligned}
\end{aligned}
$$

Normalization by $\bar{c}(1-\bar{c})$ allows comparison of systems of different $\bar{c}$ (different $w_{j} / w_{m}$ ) and bounds $U$ between 0 and 1 . $U=0$ corresponds to a perfectly mixed system, and $U=1$ a perfectly segregated system.

The objective of this investigation was to rapidly screen a variety of flow and geometric configurations and compare the experimental results to similar numerical studies. Therefore, the suitability of using an unmixedness parameter based on the mean distribution alone was studied. It was found that $U$ obtained from an ensemble of instantaneous distributions was approximately equal to that obtained from the average distribution ${ }^{9}$. Therefore, the unmixedness parameter used in this investigation is spatial unmixedness :

$$
\mathrm{U}_{\mathrm{s}}=\frac{\mathrm{c}_{\mathrm{var}}}{\mathrm{c}_{\mathrm{avg}}\left(1-\mathrm{c}_{\mathrm{avg}}\right)}
$$

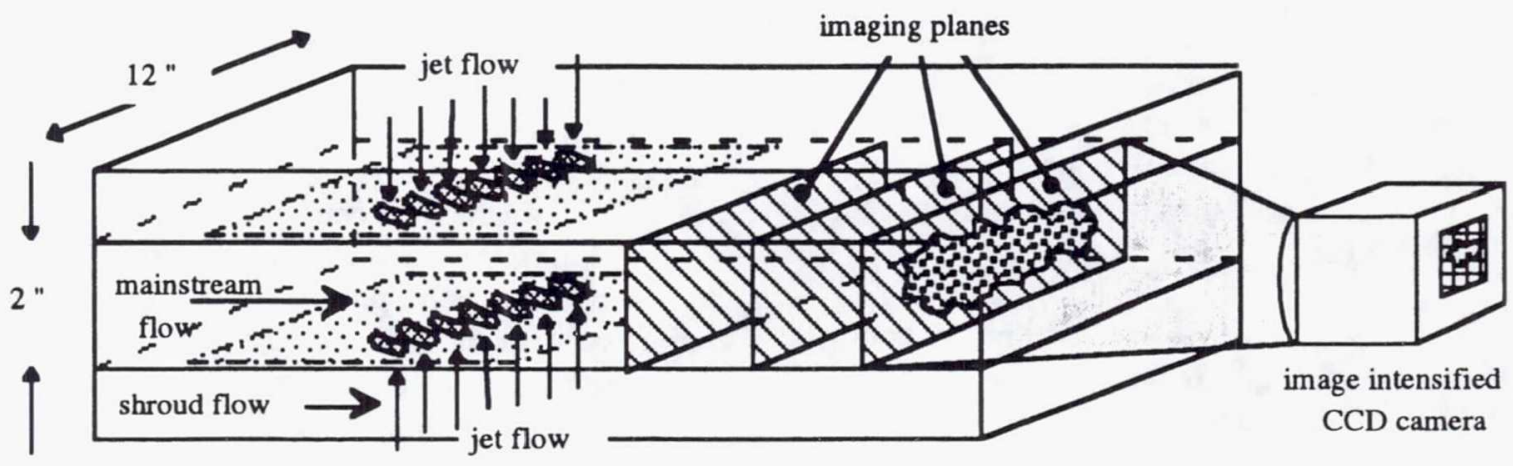

Figure 1: Experimental Configuration used to Measure Planar Concentration Distributions 
where,

$$
\begin{aligned}
\mathrm{c}_{\mathrm{var}}= & \frac{1}{\mathrm{~m}} \sum_{\mathrm{i}=1}^{\mathrm{m}}\left(\overline{\mathrm{c}}_{\mathrm{i}}-\mathrm{c}_{\mathrm{avg}}\right)^{2} \\
= & \text { spatial concentration variance } \\
\overline{\mathrm{c}_{\mathrm{i}}}= & \text { time-average concentration at a pixel } \\
\mathrm{c}_{\mathrm{avg}}= & \text { fully mixed concentration downstream of the } \\
& \text { trailing edge of the orifice }=\overline{\mathrm{c}}
\end{aligned}
$$

The measured relative light intensities are converted to measurements of concentration by normalizing so that $\frac{1}{m} \sum_{i=1}^{m} \bar{c}_{i}=c_{a v g}$, (the metered/fully mixed value). Therefore, although $\mathrm{c}_{\mathrm{avg}}=\overline{\mathrm{c}}$, the actual value of $\overline{\mathrm{c}}$ is not measured directly and cannot be computed in the same way upstream of the trailing edge of the orifice, i.e. before all of the jet mass is injected. Eq. 1 is still valid, however, if concentration is measured directly or determined by calibration using a supplemental technique (see Ref. 9, p. 4).

\section{Mixing Configurations}

Table 1 identifies 8 orifice plate configurations that were tested. The configuration sketches are drawn approximately $1 / 4$ scale in Table 1 . The configurations consisted of round holes with $\mathrm{D}=0.5,0.75$, and 0.85 and a rectangular slot with a 2:1 aspect ratio. Injection was 2-sided with the midpoints of the orifices on opposite sides either directly inline, or staggered (top wall orifice midpoints bisect the space between adjacent orifices on the bottom wall, i.e. the area ratios of the inline and staggered configurations were equivalent). Discharge coefficients were determined for each orifice plate configuration by measuring the $\Delta \mathrm{P}$ across the plate over a range of mass flows and averaging. The $C_{d}$ was used to set momentum-flux ratios of 25 and 50. (For reference,

$$
J=\left(w_{j} / w_{m}\right)^{2} /\left(\left(\rho_{j} / \rho_{m}\right)\left(C_{d}\right)^{2}\left(A_{j} / A_{m}\right)^{2}\right)
$$

Plate

Configuration

10

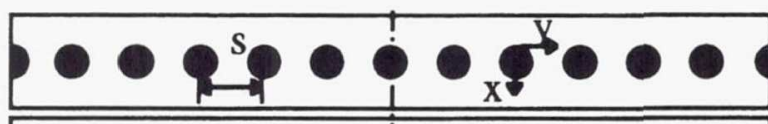

1

3

7

2
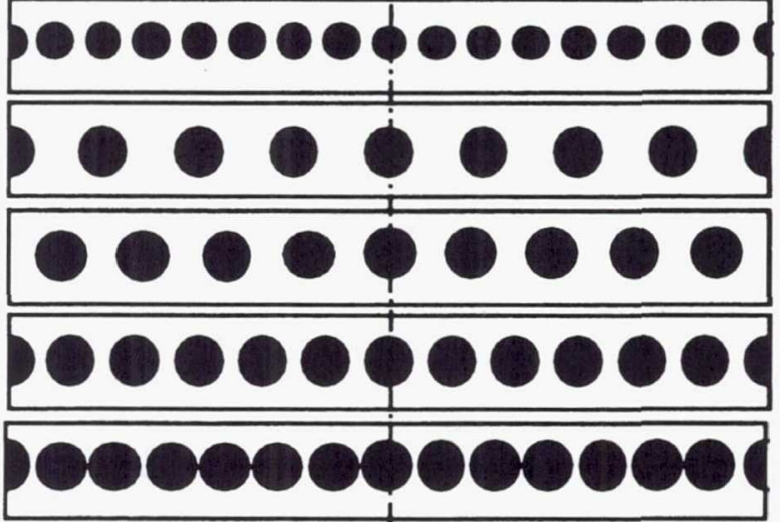

11

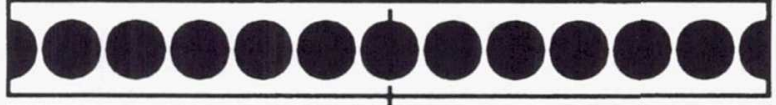

12

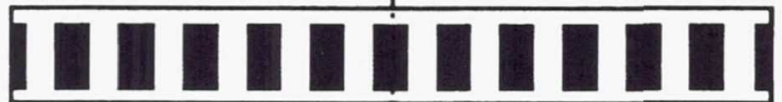

$D$ (in

0.50

0.50

0.75

0.75

0.63

0.75

0.5

0.75

0.40

0.85

0.5

$0.50 \quad 2.00$

0.38

0.75

\subsection{0}

0.29

0.6

0.375

0.50

0.35

0.6

0.375

0.60

$0.50 \quad 1.33$

0.44

0.65

0.375

0.75

$(0.5 \times 1.0) \quad 0.50$

(2.00)

0.57

$0.75 \quad 0.500$

0.50

Table 1: Orifice Plate Configurations

\footnotetext{
*

$x$ projection $/ \mathrm{H}(\mathrm{H}=2$ inches for all tests)

$\dagger y$ projection $/ \mathrm{S}$ (blockage $=$ the reciprocal of $S / D$ for the orifice configurations in Table 1)
} 
Page intentionally left blank 


\section{Orifice Spacing}

Mean concentration distributions for two-sided injection from opposing rows of round holes with the top and bottom hole centered opposite each other (inline) are shown in Fig. 2 at $x / H=0.375$ and 0.500 when $J=25$. A 10 -level color scale is used to represent contours of jet mass fraction from 0 to 1.0 (pure mainstream fluid colored red $=0$ and pure jet fluid colored dark blue $=1.0$ ). In each figure the orifice spacing decreases from $\mathrm{S} / \mathrm{H}=0.75$ in the top row to $\mathrm{S} / \mathrm{H}=0.4$ in the bottom row. Hole diameter is constant at 0.75 inches, consequently $A_{j} / A_{m}$ for plate \#9 (bottom row) is about $50 \%$ larger than plate \#3 (top row). Therefore the mass flow ratio also increases from the top row to the bottom row in Fig. 2. The fully mixed concentration, $\mathrm{C}_{\mathrm{avg}}$, i.e. the color corresponding to the fully mixed condition, is not the same contour for all of the configurations shown in Fig. 2
From Fig. 2 the effect of orifice spacing on jet penetration is clear: at a given $\mathrm{J}$, jet penetration decreases as spacing decreases. At $\mathrm{S} / \mathrm{H}=0.75$ the jet trajectories from the top and bottom walls collide at the mid-point of the duct, while at $\mathrm{S} / \mathrm{H}=0.4$ the jets remain near the walls of the duct

In previous studies by Holdeman ${ }^{2}$ jet penetration and centerplane profiles were found to be independent of orifice diameter. when $\mathrm{S} / \mathrm{H}$ and $\sqrt{\mathrm{J}}$ were inversely proportional

$$
\mathrm{S} / \mathrm{H}=\mathrm{C} / \sqrt{\mathrm{J}}
$$

An optimum S/H of 0.25 would be predicted using Eq. 3 for opposed inline orifices $(C=1.25)$ and $J=25$. In Ref. 2 the "optimum" wasobtained by visual inspection of the centerplane profiles and therefore depends on $\mathrm{x} / \mathrm{H}$.
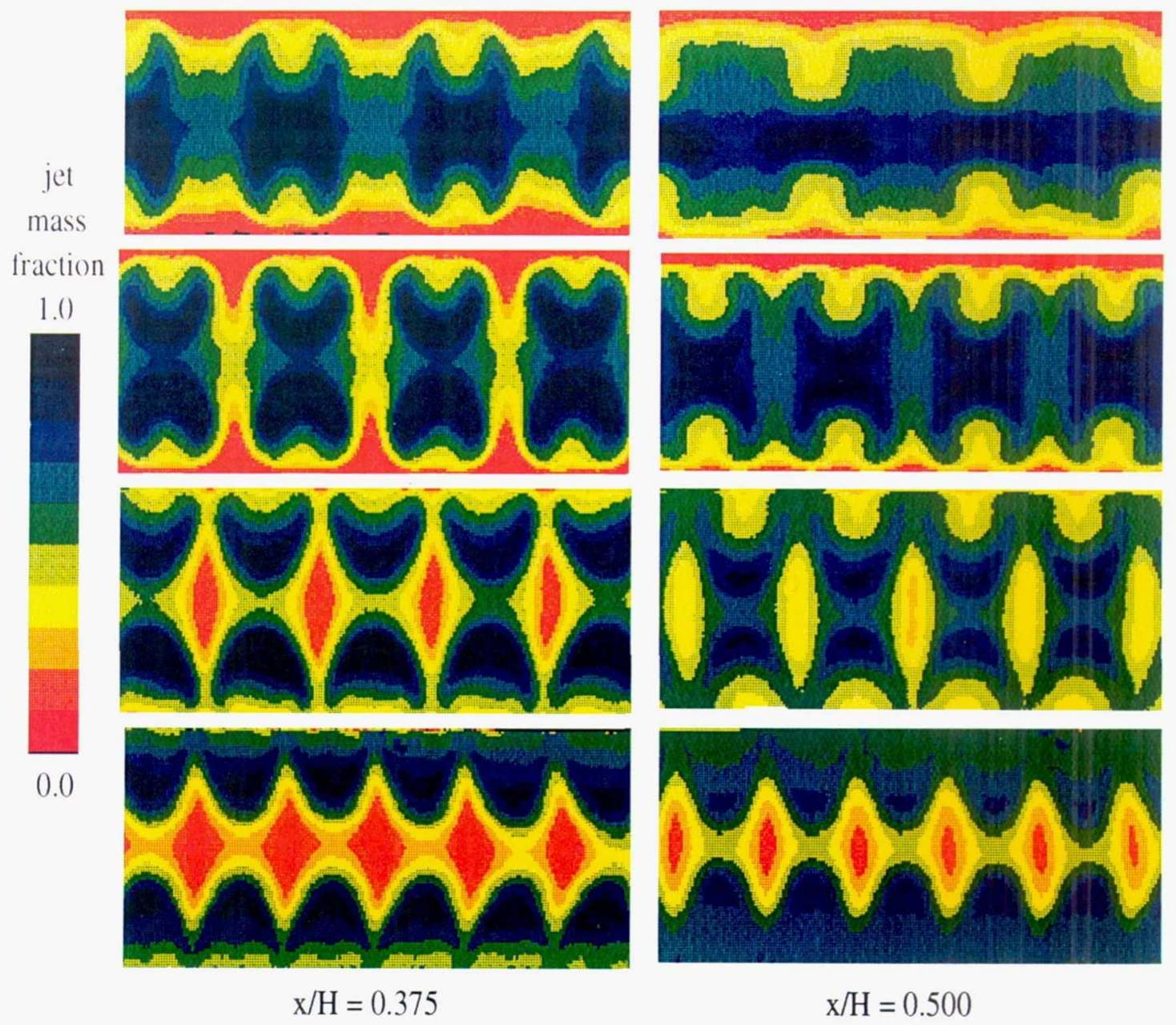

Plate \#3

$\mathrm{S} / \mathrm{H}=0.75$

Cavg $=0.49$

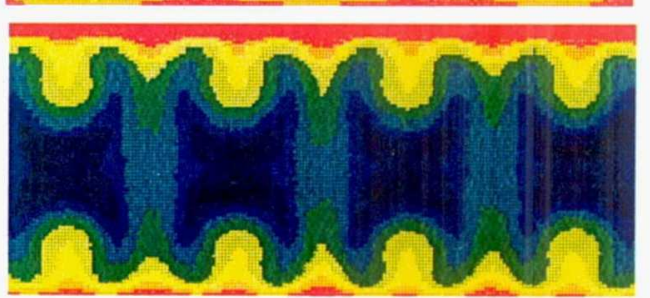

Plate \#7

$\mathrm{S} / \mathrm{H}=0.63$

Cavg $=0.53$

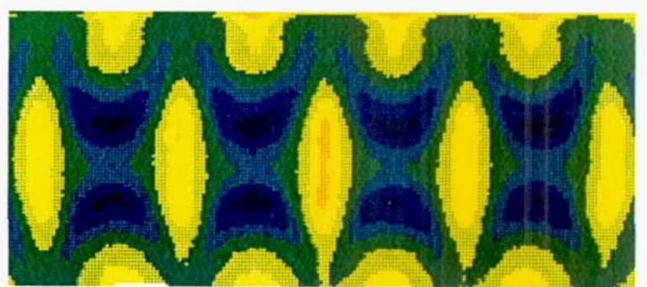

Plate \#2

$\mathrm{S} / \mathrm{H}=0.50$

Cavg $=0.59$

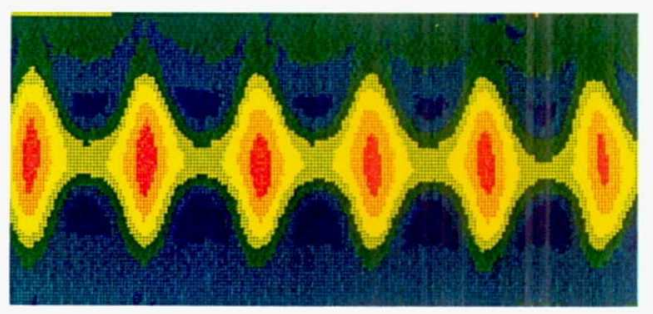

Plate \#9

$\mathrm{S} / \mathrm{H}=0.40$

Cavg $=0.64$

Figure 2: Average Concentration Distributions for Opposed Inline Round Holes ( $D=0.75^{\prime \prime}$ ) at $J=25$ 
Page intentionally left blank 
In Fig. 3 the effect of $S / \mathrm{H}$ on mixing effectiveness is shown in a plot of $U_{\mathrm{S}}$ vs downstream distance for the same configurations in Fig. 2. An optimum spacing is indicated at $\mathrm{S} / \mathrm{H}=0.5$, which corresponds to a jet penetration between the case where the jets "over-penetrate" at $\mathrm{S} / \mathrm{H}=0.75$ (top row in Fig. 2) and "under-penetrate" at $\mathrm{S} / \mathrm{H}=0.4$ (bottom row in Fig. 2 ). The orifice configuration shown as plate $\# 2$ in Table 1 provided the fastest mixing at $\mathrm{J}=25$.

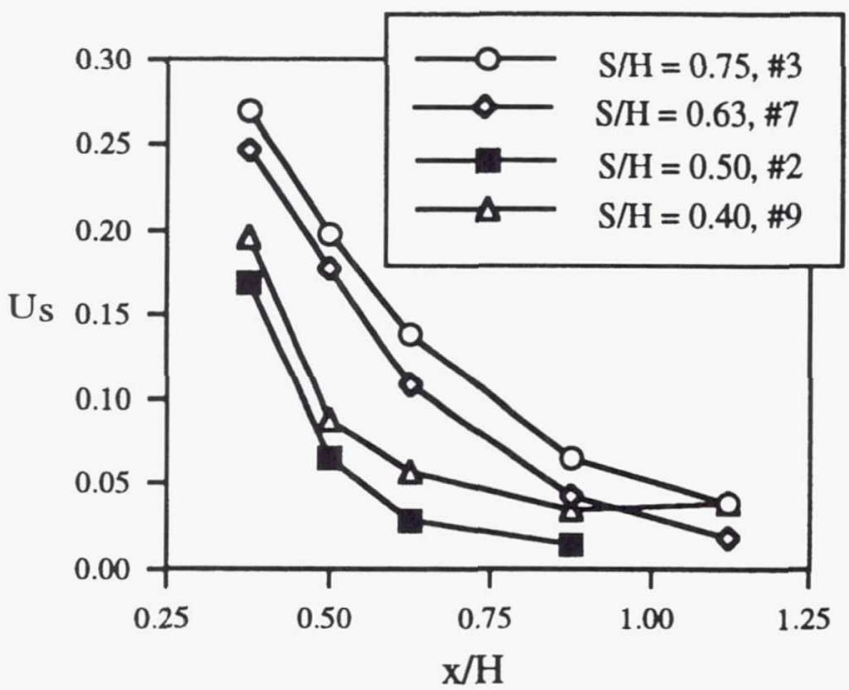

Figure 3: Effect of $\mathrm{S} / \mathrm{H}$ on Spatial Unmixedness for inline round holes $\left(\mathrm{D}=0.75^{\prime \prime}\right)$ at $\mathrm{J}=25$

Eq. 3 is evaluated in Fig. 4 at $\mathrm{J}=25$ for the fastest mixing configuration at $\mathrm{D}=0.75$ ( $\# 2$, shown previously in Fig. 3 ) and two configurations with $\mathrm{D}=0.50$ and similar values for C. Mixing was most effective for each hole size when $\mathrm{C}=\mathbf{2 . 5}$. The unmixedness curves for both plates \#2 and \#10 (Table 1) at $\mathrm{J}=25$ support Eq. 3 in that mixing rate is a function of spacing and $\mathrm{J}$, but independent of orifice diameter.

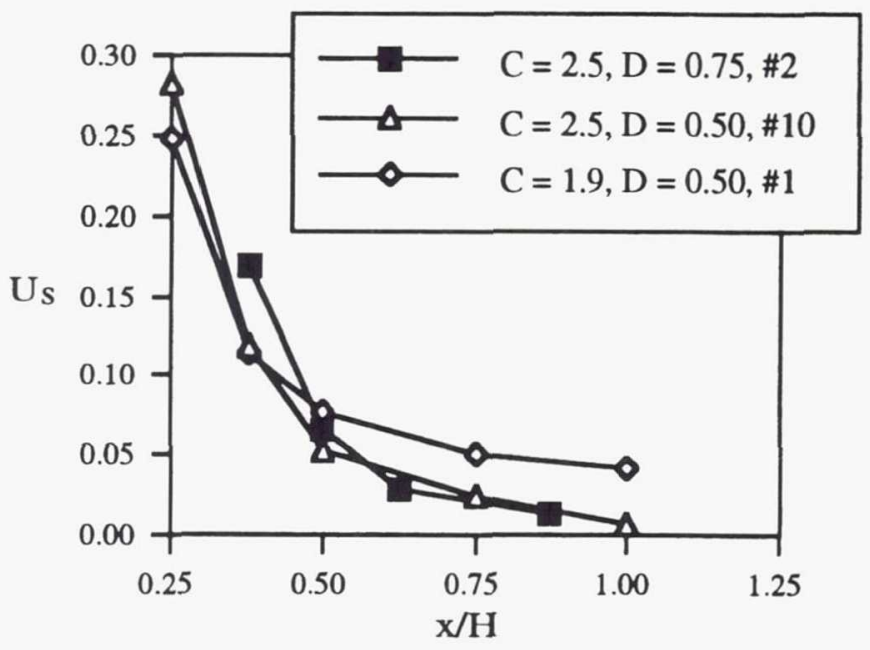

Figure 4: Effect of Orifice Diameter on Spatial Unmixedness at $\mathrm{J}=25$ for Opposed Inline Round Holes
$\mathrm{U}_{\mathrm{S}}$ is plotted as a function of $\mathrm{x} / \mathrm{H}$ at $\mathrm{J}=50$ in Fig. 5 . The values of $U_{S}$ are lower at $\mathrm{J}=50$ than at $\mathrm{J}=25$ (Figs. 3 and 4) indicating that mixing effectiveness has increased with increased $\mathrm{J}$. The best mixing was provided by orifice plate \# 1 (Table 1) which has an $\mathrm{S} / \mathrm{H}=0.38$, consistent with Eq. 3, i.e. higher values of $\mathrm{J}$ require smaller values of $\mathrm{S}$. The corresponding value for $\mathrm{C}$ was $2.7 \mathrm{vs}$. the value of 2.5 found for $\mathrm{J}=25$.

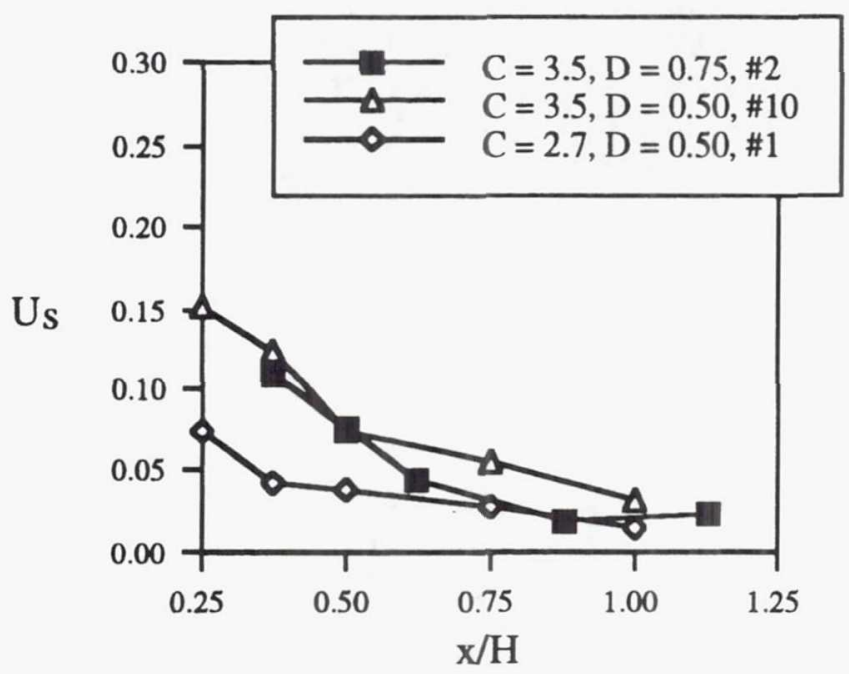

Figure 5: Effect of Orifice Diameter on Spatial Unmixedness at $\mathrm{J}=50$ for Opposed Inline Round Holes

The value of 2.5 obtained for $\mathrm{C}$ for opposed rows of inline orifices is higher than the value of 1.25 found by Holdeman. It is suspected that two factors influence the variation in C: (1) data analysis in previous studies compared centerplane profiles, while this study measures the nonuniformity of the entire duct cross section, and (2) the orifice configurations of this study are outsideof the range of the previous data set, i.e. previous $A_{j} / A_{m}<0.1$ and $S / D>2$ (widely spaced) while in this study $A_{j} / A_{m}>0.2$ and $S / D<2$ (closely spaced).

\section{Orifice Diameter and Blockage}

Eq. 3 can be used as a design tool, given J, to specify the optimum $S$ for a row of inline round holes. However, for durability reasons, it may be necessary to consider the trade-off between blockage (B)(webb between adjacent orifices) and longer injection length (rectangular slots). In the limit, when $\mathrm{B}=1, \mathrm{a} 2 \mathrm{D}$ slot is obtained which has been shown to be a poor mixer compared to a row of discrete orifices ${ }^{2}$. This would suggest that in addition to an optimum S, B is also an important consideration. Unfortunately, for round holes, B and D cannot be tested independently. A comparison of orifice plates \#10, \#2, and \#11 affords an evaluation progressively greater B, while maintaining a constant $S$. 
In Fig. $6 \mathrm{U}_{\mathrm{S}}$ is plotted as a function of $\mathrm{x} / \mathrm{H}$ at $\mathrm{J}=25$ for $\mathrm{B}=0.50,0.75$ and 0.85 . Note that for these configurations $\mathrm{B}=\mathrm{D}$ since $\mathrm{S}=1$. In addition since $\mathrm{C}=2.5$, the configurations are optimized at this $J$. The unmixedness curves for the three configurations are similar, which indicates that $\mathrm{B}$ ranging from 0.50 to 0.85 does not affect mixing rate. Even a relatively high blockage still allows the mainstream flow to squeeze between the jets and generate a 3D flowfield. However, the level of $U_{S}$ in the near-field $(x / H<0.5)$ is influenced by $D$. At $x / H<0.5$, the lowest levels of $U_{S}$ are obtained for the smallest diameter holes. Although optimum spacing as specified by Eq. 3 does not appear to be a function of $D$ (same value of $C$ is obtained independent of $D$ ), the level of $U_{S}$ at a particular value of $x / H$ is affected by the axial length of the orifice, i.e. the mixing curves shift downstream along with the trailing edge of the orifice. Fig. 6 indicates that the lowest values of $U_{S}$ are obtained in a minimum $\mathrm{x} / \mathrm{H}$ when the axial length of the orifice is minimized.

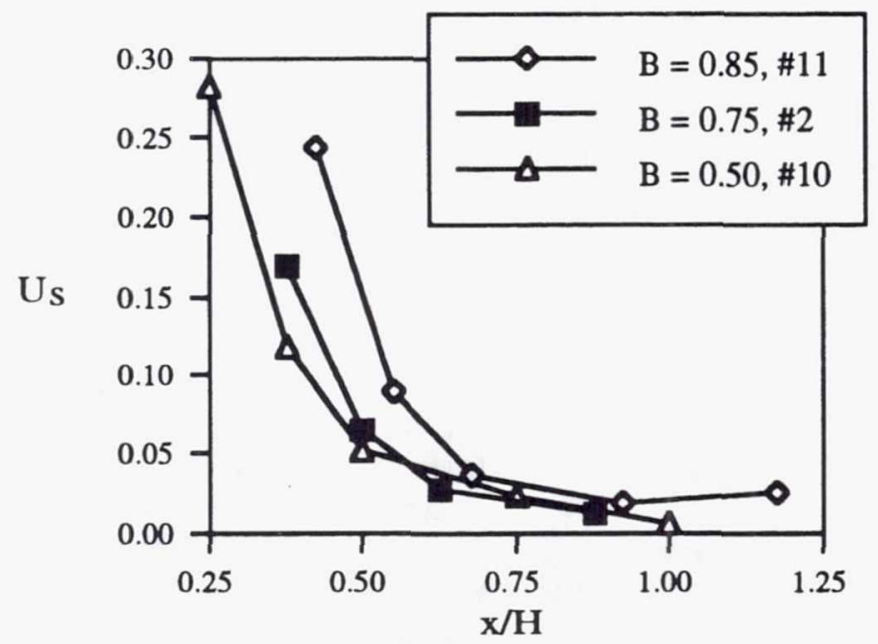

Figure 6. Effect of Blockage on Spatial Unmixedness at $\mathrm{J}=25$ for Opposed Inline Round Holes at $\mathrm{S} / \mathrm{H}=0.5$

In Fig. $7 \mathrm{U}_{\mathrm{S}}$ is shown as a function of $\mathrm{x} / \mathrm{H}$ at $\mathrm{J}=25$ for a rectangular slot with a 2:1 aspect ratio (plate\#12, Table 1) and a round hole with $\mathrm{D}=0.85$ (plate\#11, Table 1 ). The area ratios of the two configurations are equilvalent. Mixing rates of the two configurations are not the same. The levels of unmixedness are significantly higher for the slot configuration and the rate is slower. Fig. 7 further emphasizes that mixing effectiveness diminishes as axial length of injection increases. However, the problem of liner durability could be addressed by the use of rectangular slots if slot length $\approx$ hole diameter.

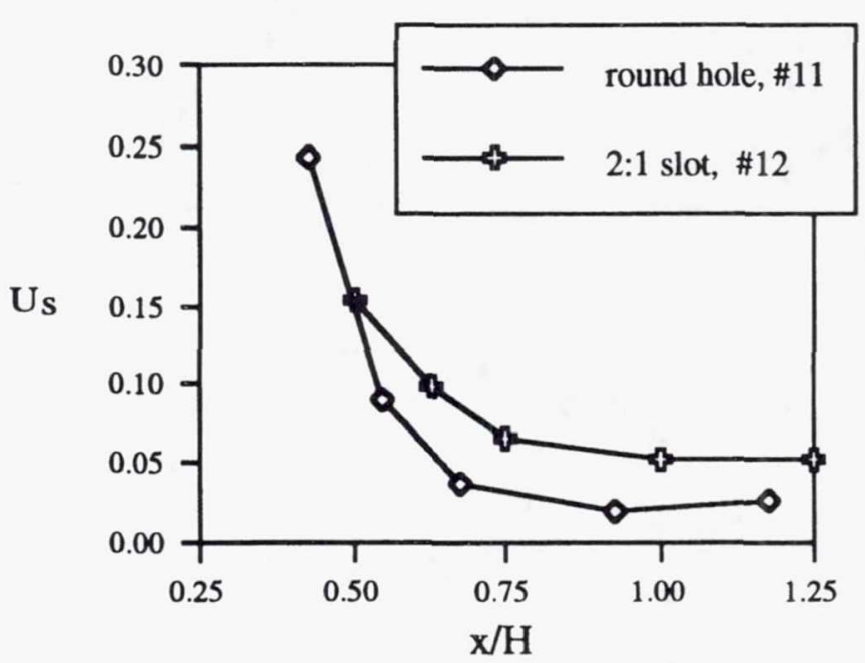

Figure 7: Comparison of Equal Area Equal S Opposed Inline Round Holes and Rectangular Slots at $\mathrm{J}=25$

\section{Inline vs. Staggered}

Opposed jet configurations are not limited to inline orientations. In Fig. 8 two examples of inline and staggered configurations are shown at $\mathrm{J}=50$ for round holes. Both configurations are for holes with $\mathrm{D}=0.75$, but the case on the left has an $S=1.0(\mathrm{~S} / \mathrm{H}=0.5)$ and the one on the right an $S=1.5(S / H=0.75)$. Note that $A_{j} / A_{m}$ (and therefore $\left.w_{j} / w_{m}\right)$ for the inline and staggered configurations are equivalent at each S/D. When $S / D=1.33$ (plate \#2), the inline and staggered distributions are very similar: the jets overpenetrate and appear to remain relatively unmixed at $\mathrm{x} / \mathrm{H}=0.625$. In contrast, at $S / D=2.00$ (plate \#3) the inline and staggered distributions are quite different. The staggered configuration appears better mixed at $\mathrm{x} / \mathrm{H}=0.625$. The staggered jets become elongated as they pass by each other. An interaction of the counter-rotating vortex pair from the top and bottom jets is indicated by the loss of the characteristic "horseshoe" shape in the near-field. It appears that the resulting vortex system is less stable than any of the other three configurations. Note that the jet fluid apparent nearest the walls in the lower right figure ( $\mathrm{S} / \mathrm{D}=2$, staggered) is from jets injected from the opposite wall, whereas the jet fluid nearest the walls in the other figures is from jets injected from the adjacent wall. 
In Fig. $9 \mathrm{U}_{\mathrm{S}}$ is plotted as a function of $\mathrm{x} / \mathrm{H}$ for the four configurations in Fig. 8. As predicted the staggered configuration is the most effective mixer. A systematic inspection of staggered configurations for the plates shown in Table 1 indicated that the staggered orientation does not increase mixing effectiveness until $\mathrm{S} / \mathrm{D}=2$, i.e. at $\mathrm{S} / \mathrm{D}<2 \mathrm{U}_{\mathrm{S}}$ curves for staggered and inline configurations were similar. The implication is that there may also be an optimum $S / D$, in addition to an optimum $\mathrm{S} / \mathrm{H}$, for staggered configurations. If the required $A_{j} / A_{m}$ can be achieved with $S / D=2$, it appears that stag gering may produce lower levels of $U_{\mathrm{S}}$ in the near-field if $\mathrm{J}$ is sufficient for the jets from opposite walls to penetrate past eachother

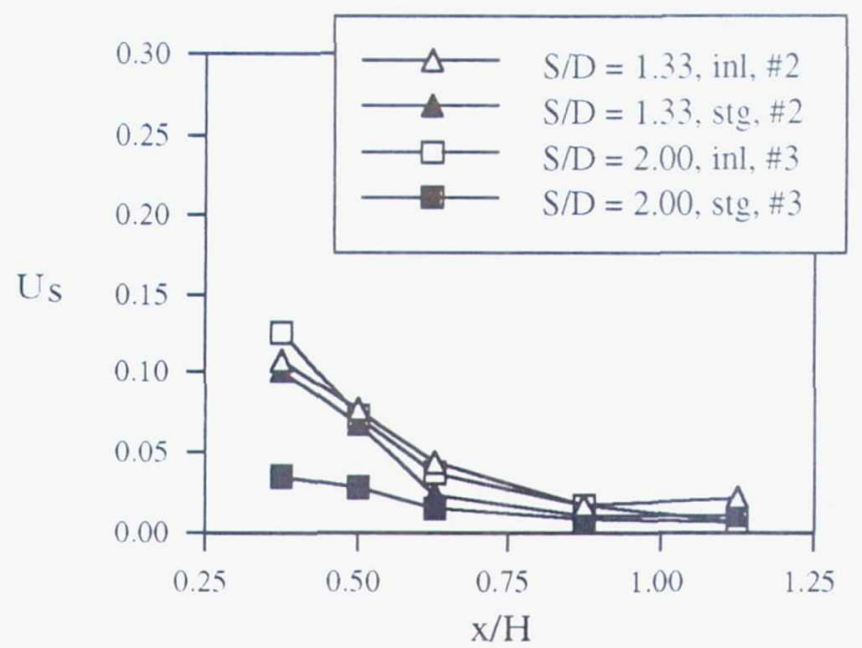

Figure 9: Effect of Orifice Orientation on Spatial Unmixedness at $\mathrm{J}=50$

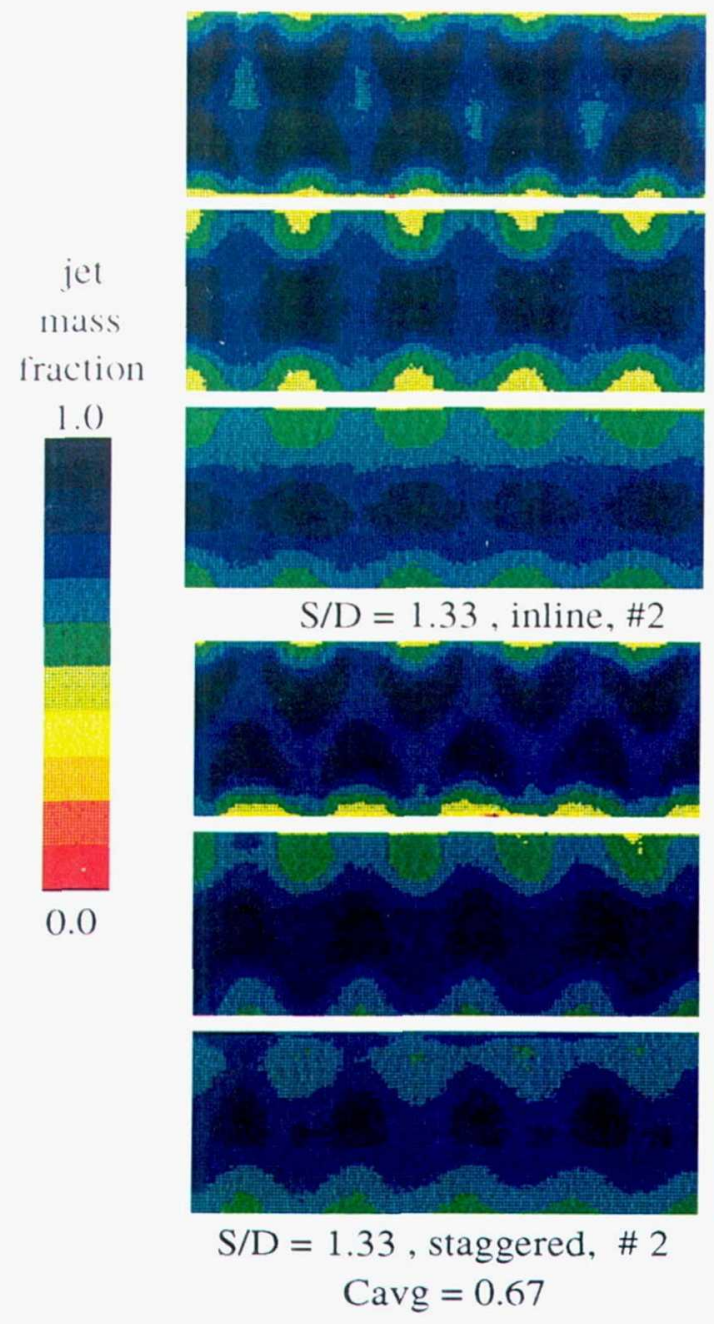

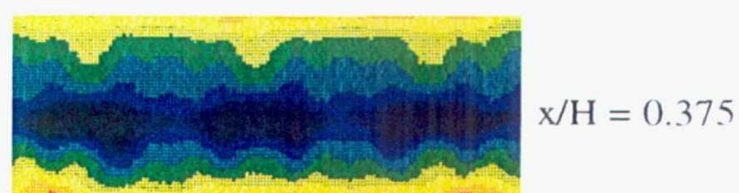
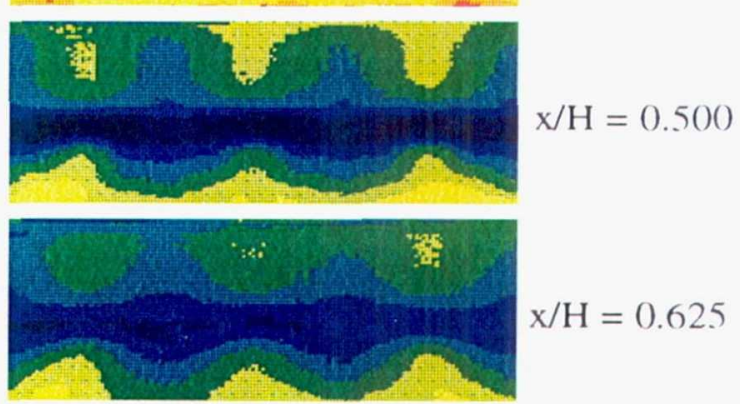

$\mathrm{x} / \mathrm{H}=0.625$

$\mathrm{S} / \mathrm{D}=2.00$, inline, $\# 3$

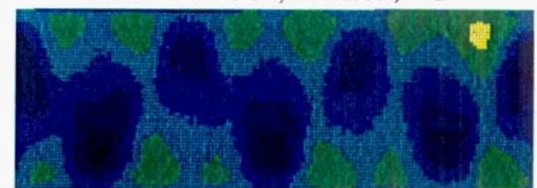

$\mathrm{x} / \mathrm{H}=0.375$

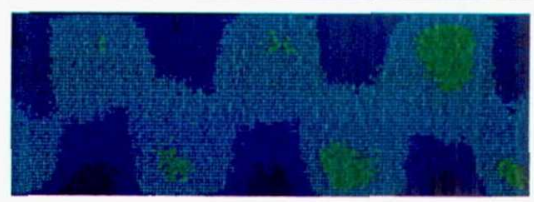

$\mathrm{x} / \mathrm{H}=0.500$

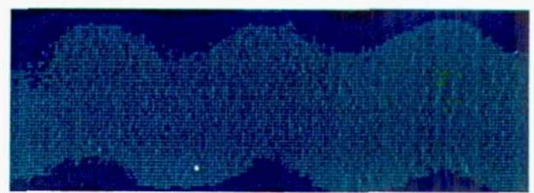

$\mathrm{S} / \mathrm{D}=2.00$, staggered, $\# 3$

Cavg $=0.57$

Figure 8: Comparison of Staggered and Inline Orientations at $\mathrm{J}=50$ 
Page intentionally left blank 


\section{Conclusions}

1. As found in previous studies by Holdeman, mixing effectiveness can be characterized by:

$$
\mathrm{C}=(\mathrm{S} / \mathrm{H}) * \sqrt{ } \mathrm{J}
$$

The optimum value obtained for $C$ for opposed inline round holes in this study was 2.5 .

2. For opposed rows of round holes with centerlines inline, mixing was similar for blockages ranging from 0.5 to 0.75 .

3. Lower levels of $U_{S}$ were obtained as a function of downstream distance when the diameter, or length, of the orifice was minimized.

4. The vortex pattern formed by jets staggered at $S / D=2$ appears to destabilize more quickly than that from inline jets. Therefore, properly spaced staggered orientations may augment mixing.

\section{Acknowledgments}

This work was supported by NASA Contract NAS3-25954, Task Order \#12.

\section{References}

1. Shaw, R.J., "Engine Technology Challenges for a 21st Century High Speed Civil Transport," AIAA 10th International Symposium on Air Breathing Engines, September 1-6, 1991 (also NASA TM 104361).

2. Holdeman, J.D., "Mixing of Multiple Jets with a Confined Subsonic Crossflow," AIAA Paper 91-2458, Sacramento, CA, June 1991 (also NASA TM 104412).

3. Smith, C.E., "Mixing Characteristics of Dilution Jets in Small Gas Turbine Combustors," AIAA Paper 90-2728, Orlando, Fl, July 16-18, 1990.
4. Bain, D.B., Smith, C.E., and Holdeman, J.D., "CFD Mixing Analysis of Jets Injected from Straight and Slanted Slots into Confined Crossflow in Rectangular Ducts," AIAA 92-3087, Nashville, TN, July 6-8, 1992 (also NASA TM 105699).

5. Liscinsky, D.S., True, B., Vranos, A., and Holdeman, J.D., "Experimental Study of Cross-Stream Mixing in a Rectangular Duct," AIAA Paper 92-3090, Nashville, TN, July 6-8, 1992 (also NASA TM 106194).

6. Liscinsky, D.S., Vranos, A., and Lohmann, R.P., "Experimental Study of Crossflow Mixing in Cylindrical and Rectangular Ducts," NASA CR 187141, March 1993.

7. Talpallikar, M.V., Smith, C.E., Lai, M.C., and Holdeman, J.D., "CFD Analysis of Jet Mixing in Low $\mathrm{NO}_{\mathrm{x}}$ Flametube Combustors," AIAA Paper91-217, 1991 (also NASA TM 104466).

8. Smith, C.E., Talpallikar, M.V., and Holdeman, J.D., "A CFD Study of Jet Mixing in Reduced Areas for Lower Combustor Emissions," AIAA Paper 91-2460, Sacramento, CA, June 1991 (also NASA TM 104411).

9. Vranos, A., Liscinsky, D.S., True, B., and Holdeman, J.D., "Experimental Study of Cross-Stream Mixing in a Cylindrical Duct," AIAA Paper 91-2459, Sacramento, CA, June 24-27, 1991 (also NASA TM 105180).

10. Hatch, M.S., Sowa, W.A., Samuelsen, G.S., and Holdeman, J.D., "Jet Mixing Into a Heated Cross Flow in a Cylindrical Duct: Influence of Geometry and Flow Variations," AIAA Paper 92-0773, Reno, Nevada, Jan. 6-9, 1992 (also NASA TM 105390).

11. Oechsle, V.L., Mongia, H.C., and Holdeman, J.D., "A Parametric Numerical Study of Mixing in a Cylindrical Duct," AIAA-92-3088, Nashville, TN, July 6-8, 1992 (also NASA TM 105695).

12. Kroll, J.T., Sowa, W.A., Samuelsen, G.S., and Holdeman, J.D., "Optimization of Circular Orifice Jets Mixing into a Heated Crossflow in a Cylindrical Duct," AIAA Paper 930249, Reno, Nevada, Jan. 11-14, 1993.

13. Danckwertz, P.V., "The Definition and Measurement of Some Characteristics of Mixtures," Appl. Sci. Res., Sec. A, Vol. 3, 1952, pp. 279-296. 
Public reporting burden for this collection of information is estimated to average 1 hour per response, including the time for reviewing instructions, searching existing data sources, gathering and maintaining the data needed, and completing and reviewing the collection of information. Send comments regarding this burden estimate or any other aspect of this Davis Highway, Suite 1204, Arlington, VA 22202-4302, and to the Office of Management and Budget, Paperwork Reduction Project (0704-0188), Washington, DC 20503.

\begin{tabular}{|l|l|l|}
\hline 1. AGENCY USE ONLY (Leave blank) & $\begin{array}{c}\text { 2. REPORT DATE } \\
\text { June } 1993\end{array}$ & $\begin{array}{r}\text { 3. REPORT TYPE AND DATES COVERED } \\
\text { Technical Memorandum }\end{array}$ \\
\hline
\end{tabular}

4. TITLE AND SUBTITLE 5. FUNDING NUMBERS

Experimental Investigation of Crossflow Jet Mixing in a Rectangular Duct 6. AUTHOR(S) WU-537-02-21

D.S. Liscinsky, B. True, and J.D. Holdeman

7. PERFORMING ORGANIZATION NAME(S) AND ADDRESS(ES)

8. PERFORMING ORGANIZATION REPORT NUMBER

National Aeronautics and Space Administration

Lewis Research Center

Cleveland, Ohio 44135-3191

E-7834

9. SPONSORING/MONITORING AGENCY NAME(S) AND ADDRESS(ES)

10. SPONSORING/MONITORING AGENCY REPORT NUMBER

National Aeronautics and Space Administration

Washington, D.C. 20546-0001

NASA TM-106152

AIAA-93-2037

\section{SUPPLEMENTARY NOTES}

Prepared for the 29th Joint Propulsion Conference and Exhibit cosponsored by the AIAA, SAE, ASME, and ASEE, Monterey, California, June 28-30, 1993. D.S. Liscinsky and B. True, United Technologies Research Center, East Hartford, Connecticut 06108, and J.D. Holdeman, NASA Lewis Research Center. Responsible person, J.D. Holdeman, (216) 433-5846.

12a. DISTRIBUTION/AVAILABILITY STATEMENT 12b. DISTRIBUTION CODE

Unclassified - Unlimited

Subject Category 07

13. ABSTRACT (Maximum 200 words)

An experimental investigation of the mixing of nonreacting opposed rows of jets injected normal to a confined rectangular crossflow has been conducted. Planar Mie-scattering was used to measure the time-average concentration distribution of the jet fluid in planes perpendicular to the duct axis. The mixing effectiveness of round orifice injectors was measured as a function of orifice spacing and orifice diameter. Mixing effectiveness was determined using a spatial unmixedness parameter based on the variance of mean jet concentration distributions. Optimum mixing was obtained when the spacing-toduct-height ratio was inversely proportional to the square root of the jet-to-mainstream momentum-flux ratio. For opposed rows of round holes with centerlines inline, mixing was similar for blockages up to $75 \%$. Lower levels of unmixedness were obtained as a function of downstream location when axial injection length was minimized. Mixing may be enhanced if orifice centerlines of opposed rows are staggered, but note that blockage must be $\leq 50 \%$ for this configuration.

14. SUBJECT TERMS

Dilution; Jet mixing flow; Gas turbine; Combustion chamber; Emissions

15. NUMBER OF PAGES

12

16. PRICE CODE

$\mathrm{A} 03$

17. SECURITY CLASSIFICATION OF REPORT

Unclassified
18. SECURITY CLASSIFICATION OF THIS PAGE

Unclassified
19. SECURITY CLASSIFICATION OF ABSTRACT

Unclassified 
National Aeronautics and Space Administration

Lewis Research Center

Cleveland, Ohio 44135

Omelet Ruelnees

Penelty tor Privete Uee 8000
FOUFTH CLASS MAIL

ADDRESS COARECTION REQUESTED 